Studia Rossica Gedanensia, 6/2019, 185-194, ISSN 2392-3644 (online), ISSN 2449-6715 (print) DOI: https://doi.org/10.26881/srg.2019.6.14

\title{
ФЕНОМЕН ГУМАНИТАРНОЙ ЭКСПЕРТИЗЫ \\ В СОВРЕМЕННЫХ УСЛОВИЯХ: АКСИОЛОГИЧЕСКИЙ, НАУЧНЫЙ И КОММУНИКАТИВНЫЙ АСПЕКТЫ ${ }^{1}$
}

\author{
ВЕРА БЕЛОКРЫЛОВА \\ Национальная академия наук Беларуси \\ Институт философии \\ Центр управления знаниями и компетенциями \\ ул. Сурганова 1/2, 220072, г. Минск, Беларусь \\ e-mail: ralfinaster@gmail.com \\ ORCID: https://orcid.org/0000-0002-4306-8991 \\ (получено 3.10.2019; принято 10.10.2019)
}

\section{Abstract \\ Phenomenon of Humanistic Expertise in Modern Conditions: Axiological, Scientific and Communicative Aspects}

In the paper the triune nature and the main methodological components of humanistic expertise are shown: "attribution to value", "attribution to science", and "attribution to practice". The specifics of the conservative, critical, and projective expert position is explicated. The author considers the ways to increase social significance of humanistic expertise in modern conditions.

Key words: evaluation criteria, expert knowledge, humanistic expertise, socio-humanistic technologies

\footnotetext{
1 Статья подготовлена в рамках проекта «Антропологические и аргументологические основания межкультурного взаимодействия и диалога культур», выполняемого при поддержке Белорусского республиканского фонда фундаментальных исследований, договор № Г18Р-211 от 30.05.2018 г.
} 


\section{Резюме}

Обоснован триединый характер и проанализированы основные методологические компоненты гуманитарной экспертизы: «отнесение к ценности», «отнесение к науке» и «отнесение к практике»; эксплицирована специфика консервативной, критической и проективной позиции эксперта. Рассмотрены пути повышения общественной значимости гуманитарной экспертизы в современных условиях.

Ключевые слова: гуманитарная экспертиза, оценочные критерии, социогуманитарные технологии, экспертное знание

Широкое обсуждение возможностей и атрибутов гуманитарной экспертизы берет свое начало еще в годы перестройки вместе с идей общественного контроля и приоритетности гуманного, человеческого измерения политики и экономики. В современном научном и управленческом дискурсе термин «гуманитарная экспертиза» пользуется неизменной популярностью, употребляется в многочисленных смысловых контекстах, однако содержательно, концептуально, а главное, методологически он по-прежнему остается достаточно неопределенным. Что специфицирует гуманитарную экспертизу, позволяет отделить ее от научного знания, этических суждений и общественного мнения? Каким образом в гуманитарной экспертизе взаимодействуют и ранжируются указанные компоненты?

Экспертное знание традиционно соединяет практику и науку, но не совпадает полностью ни с одной из них.

Чем экспертиза отличается от других гуманитарных практик? Вообще экспертиза определяется через лакуну в знании, когда не хватает каких-то знаний для объяснения явления, его причин. (...) Речь идет о каких-то новых или полностью не сводимым к традиционным формам практики, то мы не можем основываться на достоверном знании. В такой ситуации возникает альтернатива выбора одного из двух способов совладания с неопределенностью: либо вера, либо экспертиза (Леонтьев 2018: 122).

В указанном пункте мы можем зафиксировать важный аспект имманентной противоречивости феномена гуманитарной экспертизы, который возникает в пространстве соприкосновения систем аргументации научной рациональности и самоценного аксиологического суждения. «Гуманитарная экспертиза не может не быть делом нравственным» (Богомяков 1992: 120). Таким образом в содержании гуманитарной экспертизы так или иначе представлена апелляция и к научному знанию, и к сфере ценностей. Аксиологическое и теоретическое взаимодействуют в диапазоне от конкуренции до взаимного обоснования именно через коммуникативный контекст и могут присутствовать в продуктах в различных, по сути, «договорных» пропорциях.

Предметная область гуманитарной экспертизы также заслуживает обсуждения. На протяжении нескольких десятилетий представления о сущности и на- 
значении гуманитарной экспертизы претерпели трансформацию. На сегодняшний день не сформирована единая позиция по поводу назначения и пределов гуманитарной экспертизы. В качестве идеально-типических подходов целесообразно выделить психологизаторский, технологизаторский и сциентистский.

В каком случае необходима именно гуманитарная экспертиза, а не, к примеру, научный прогноз или общественное обсуждение? Мы разделяем позицию, согласно которой, гуманитарная экспертиза уместна в случае, если явление или процесс становится значимым компонентом общественной практики; однако при этом в силу новизны, комплексности, междисциплинарности не очевидны основания его научного объяснения, критерии этической оценки дискуссионны, а также есть основания полагать наступление кумулятивного эффекта и долгосрочных системных последствий. Распространенная направленность гуманитарной экспертизы - процессы активного освоения новых регионов реальности, новые формы и разновидности социокультурных взаимодействий, а также сопровождающие их латентные социальные процессы. Здесь от гуманитарной экспертизы ожидают обнаружение пределов социальных инноваций и преобразовательной деятельности, переступать которые не следует ни при каких обстоятельствах (Богомяков 1992: 116).

Основные составные компоненты гуманитарной экспертизы - это «отнесение к ценности», «отнесение к науке» и «отнесение к практике». Это предполагает, во-первых, рефлексивную экспликацию коммуникативного ландшафта процедуры «оценивания». Смысловые параметры, критерии и стандарты экспертной деятельности должны в первую очередь становиться предметом экспертной рефлексии. «Гуманитарная экспертиза строится относительно некого нормативно-ценностного базиса, ее результаты релятивны и релевантны относительно этого базиса. Гуманитарная экспертиза всегда относительна и конкретна» (Тульчинский 2008: 47). Г.Л. Тульчинский усматривает ядро гуманитарной экспертизы в соотнесении нормативно-ценностных комплексов различного уровня: национального, этнического, конфессионального, возрастного, профессионального. Однако, на наш взгляд, ограничение исключительно «отнесением к ценности» делает гуманитарную экспертизу неотличимой от этического обсуждения. Достаточно дискуссионным представляется утверждение цитируемого автора, сводящего специфику гуманитарной экспертизы к выявлению влияния психологических особенностей людей на социальные события и влияния социальных событий на психологические особенности людей (Тульчинский 2008: 46). Подобная психологизация экспертизы превращает ее в более или менее авторитетное суждение, основанное на определенных ценностных предпосылках, что лишает экспертное знание какой бы то ни было общезначимости и универсальности.

Абсолютизируя роль личностного фактора, цитируемый автор в буквальном смысле переворачивает соотношение социально-технологического и личностного в социальной практике. В его трактовке личностная ориентированность современных социальных технологий сводится к их гибкой подстройке под уникального индивида. Тульчинским справедливо подчеркивается гуманитарная зависимость функционирования современных экономических институтов: 
персонал-ориентированные технологии менеджмента, индивидуализированный маркетинг, пиар, ориентированный на особенности восприятия целевой аудитории и т.п. Однако сущность социальных технологий, разработчики которых активно обращаются к услугам гуманитарной экспертизы, - в преобразовании своего объекта в соответствии с заранее заданным планом и критериями. Всякая технология (и гуманитарная не представляет здесь исключения) подстраивает, а не подстраивается. Экспертное знание здесь важно для уяснения специфики объекта преобразования, выработки индивидуализированного алгоритма воздействия на него.

Социогуманитарные технологии - это сложный, многоаспектный и амбивалентный феномен современности, тесно интегрированный в структуры информационного общества. Ставшую крылатой формулу К. Маркса из Тезисов o Фейербахе - «не просто объяснять, но изменять» окружающий мир, социогуманитарные технологии реализуют в различных целях и разнообразными способами.

Не все социогуманитарные технологии одинаково гуманны. Более того, дистанция между императивом эффективности и императивом гуманизма постоянно увеличивается. Как ни парадоксально, гуманитарные, отнюдь, не обязательно означают гуманные и конструктивные. Ключевым параметром технологии как таковой является эффективность; социогуманитарные технологии, ориентированные на моделирование поведения и сознания людей в определенном направлении, здесь не представляют исключения.

Суждение формата «источник всего разнообразия современного единого мира корениться в сердце каждой уникальной личности» (Тульчинский 2008: 47), несомненно, является выражением аксиологической позиции, но никак не форматом гуманитарной экспертизы. Триединый характер гуманитарной экспертизы, исходящей не только из аксиологических, но и из научно-теоретических оснований и актуальных параметров и потребностей коммуникации (социального праксиса) является принципиальным для ее самоопределения и поддержания социального престижа на должном уровне.

Для уяснения категориальных и методологических оснований гуманитарной экспертизы принципиальным является позиция - что считать гуманитарностью? Слово «гуманитарный» используется «в двух смыслах, что нашло отражение» в словарях: 1) обращенность «к человеческой личности, к правам и интересам человека», 2) «относящийся к циклу наук о человек и культуре» (Туманов 2017: 107-108). Таким образом аксиологическо-сциентистский дуализм понятия «гуманитарная экспертиза» проявляется уже на уровне языка.

Уместным будет подробнее остановиться на ключевых для интерпретации природы гуманитарной экспертизы фигурах - заказчике и исполнителе экспертизы. Эксперт - это, как правило, специалист, который может посредством комбинации своих научных, моральных и коммуникативных компетенций восстановить недостающие звенья в теоретической либо аксиологической интерпретации практической проблемы.

Интересное предположение по поводу роли профессиональной интуиции и неэксплицированного знания высказывают В.И. Бакштановский и А.Ю. Со- 
гомонов. По их мнению, квалифицированный специалист, эксперт способен реагировать на меньшее количество информации. Отличительная черта «экспертного метода» - комплексное, нерасчлененное, «антианалитическое» освоение ситуации. «Советуясь с ученым как с экспертом, обращаясь к его мнению, мы рассчитываем прежде всего на его интуицию, профессиональная база которой позволяет ему дать нужную рекомендацию» (Бакштановский 1992: 193).

Г.Э. Тищенко актуализирует внимание на перспективах функционирования гуманитарной экспертизы как способа сохранения и поддержания множественности позиций в мультикультурном обществе и их открытого общественного диалога.

Важнейшим шагом на пути к некоторому общему решению в отношении сложнейших проблем, порождаемых научно-техническим и социальным прогрессом, является не сглаживание и игнорирование, а обнаружение различий и предоставление им возможности адекватно выразить свое содержание. Без выявления различий интересов и ценностей нельзя строить процедуры их согласования путем обсуждений (Тищенко 2008: 125).

В идее этического комитета как раз и предположена необходимость обсуждения различий и поиска согласованных решений. С учетом выявляемой сложности, различных интересов и позиций, граждане используют легитимные механизмы формирования коллективной воли для принятия морально обоснованного решения в форме закона, декларации принципов, административных норм и т.д. Важным представляется замечание цитируемого автора относительно принципиальной невозможности в гуманитарной экспертизе «окончательного решения»:

В каком-то смысле в идеологии гуманитарной экспертизы меняется сама идея «решения» проблемы. (...) Решение заключается в сложном движении мысли. Во-первых, в прояснении всей глубины и парадоксальности встающих проблем за счет мультидисциплинарного обсуждения. Во-вторых, в поиске таких идейно нейтральных «развязок», которые давали бы возможность каждому индивиду, оказавшемуся в ситуации выбора, поступить так или иначе именно в силу своих особых этических предпочтений. И, наконец, в сохранении и постоянном углублении самой проблемности (Тищенко 2008: 126).

По мнению автора, данный феномен незавершенности отражает идея гуманитарной экспертизы как длящегося мониторинга проблем, принятых решений и отслеживания отдаленных последствий.

«Оценочная» функция является, пожалуй, самой распространенной в дефинициях гуманитарной экспертизы. Так, С.В. Туманов, А.А. Оносов, Н.Е. Савина определяют гуманитарную экспертизу через оценку социальных процессов и способов их регулирования (Туманов 2017). Критериями оценки служит их соответствие актуальным общественным интересам и потребностям, и, что существенно, отдаленные социальные последствия того или иного решения. Таким образом, в гуманитарной экспертизе, кроме аксиологического критерия, оценочные функции выполняют критерии практической целесообразности. Важная роль в экспертной деятельности гуманитариев отводится также прогностическому критерию, позволяющему судить о вероятных последствиях, соотносить цели, средства и сопутствующие риски определенных решений 
и действий. При этом представления о тенденциях, как правило, производны из определенных научно-теоретических представлений о природе и механизмах функционирования объектов, характере и направленности протекания в них интересующих экспертов процессов.

Внедрение гуманитарной экспертизы в управленческую практику на институциональной основе имеет все шансы не только повысить уровень этической ответственности, но и сделать решения, принимаемые кулуарно, предметом широкого общественного обсуждения. Подобное со-творчество, соответствующее духу коммуникативной рациональности, за счет введения дополнительных переменных и факторов не способствует ускорению и упрощению принятия управленческого решения, однако делает его более взвешенным и оптимальным.

Важнейшая миссия гуманитарной экспертизы состоит в том, чтобы исключить неизбежно ограниченную компетентность и субъективизм в сфере управления. Это средство повышения эффективности управленческих решений за счет прогностики и просчета эффектов относительно различных субъектов, чьи интересы затрагиваются. Таким образом, полноценная гуманитарная экспертиза специфицируется, во-первых, научной проработкой, во-вторых, служит местом общественной дискуссии в ситуации несовпадающих ценностей и интересов. За счет мультиагентного участия гуманитарная экспертиза обеспечивает многомерную оценку характера влияния и последствий управленческой и иной социально-проектной деятельности. За счет экспертного сообщества и заинтересованных представителей общественности не просто расширяется горизонт принятия управленческого решения, но и улучшается обратная связь, а значит, и демократичность решения, что обеспечивает его поддержку на местах.

Гуманитарная экспертиза вынуждена постоянно достигать внутреннего баланса между своими основными составляющими - научным, аксиологическим и практическим компонентами. В ходе центрального для экспертизы процесса оценивания должно быть достигнуто равновесие между авторитетом научного видения проблемы и установками, желаниями, тревогами, ценностями рядовых обывателей. Третьим неотъемлемым фактором служит императив эффективности (соотношение социальных издержек и позитивного эффекта).

Аксиология тесно переплетена с культурными и социальными контекстами, которые, в принципе, не могут быть единообразными и однозначными. Цель науки - получение нового знания, цель научной экспертизы - оценка объекта с применением имеющихся в распоряжении науки объяснительных схем. Экспертиза с позиций науки предполагает применение отвечающих критериям научности инструментов, а также научную конвертируемость выводов. Очевидно, что внедрение научного знания в практику способствует его приросту, некоторые научные представления могут быть уточнены, или, напротив, подвергнуты сомнению. Однако этот принцип не работает в случае экспертной процедуры по аксиологическим основаниям. Здесь гуманитарная экспертиза - это не столько отнесение к знанию, сколько отнесение к ценности, установка определенной корреляции между знанием и ценностью. 
Эксперт, по своей сути, - это профессионал, умеющий найти общее в частном и потому адекватно оценивающий это частное. (...) специфическая задача экспертизы - служить своеобразным «мостом», одним из «связующих звеньев» между наукой и общественной практикой (Туманов 2017: 100).

К гуманитарной экспертизе зачастую прибегают в случае острой разбалансированности, противоречия между управленческими целями, массовыми ожиданиями и желаниями общественности и алгоритмами действия, дедуцируемым из научных теорий. При этом на практике последнее слово зачастую остается за ценностными предпочтениями эксперта.

Парадокс экспертизы состоит в том, что субъективное мнение и оценка эксперта, отобранного по профессиональным критериям, благодаря его более объемному и глубокому видению оказываются более объективными, то есть приближенными к реальности, чем согласованное мнение множества рядовых представителей популяции (Иванченко 2008: 38).

Однако привилегированная позиция профессионала-эксперта разделяется далеко не всеми исследователями: «Оформилась и новая антиномия: экспертиза как профессиональные суждения специалистов или как мнение любого и всех» (Бакштановский 1992: 191).

Особого внимания и настороженности заслуживает феномен симуляции гуманитарной экспертизы, когда мнения специалистов привлекаются исключительно для придания большей легитимности уже реализуемому проекту/ решению. Это означает подчинение экспертной деятельности не поиску оптимального решения и просчитыванию его системных последствий, а идеологическим и прочим утилитарным целям. Коммерческие перспективы гуманитарной экспертизы могут быть весьма привлекательными, но при этом потребность в гуманитарной экспертизе будет фактически определяться ее симуляцией, как пророчески отмечал советский исследователь А.Б. Франц еще в начале 90-х годов (Франц 1992: 213). «Убедительно симулированная наука, преподнесенная достаточно артистично, с подобающим оптимизмом, необходимой долей уверенности в успехе в обозримом будущем непременно будет вызывать симпатии и пользоваться спросом» (Франц 1992: 214).

Гуманитарная экспертиза в рыночных условиях не может полностью избежать коммодификации. Привлекательные гуманистические интенции индустриальной цивилизации, связанные с самоценностью человека, свободой, творческим началом - вот та почва, на которой взошли побеги гуманитарной экспертизы (Франц 1992: 214). В историческом ракурсе цитируемый автор выделяет «три источника и три составные части» гуманитарной экспертизы на постсоветском пространстве. Это западная индустриальная социология и психология, институт изучения общественного мнения и уходящее корнями в советскую идеологию убеждение, что «все во имя человека и для блага человека» (Франц 1992: 210).

Очевидно, что оценивающий характер экспертизы во многом зависит от того, из каких установок, концепций, мировоззрений исходит эксперт. «Подлинная гуманитарная экспертиза должна опираться на некий глобальный проект че- 
ловеческой истории, только из перспективы которого возможно принятие понастоящему экспертных решений» (Моисеев 2009: 151). Для иллюстрации данного суждения возьмем, например, экспертную деятельность, направленную на выявление признаков оскорбления чувства верующих в современной России. А что, если установки не совпадают в силу различия культурных, социальных, идеологических предпочтений экспертов, у каждого из которых своя правда? Следует ли согласиться с утверждением о том, что «гуманитарная экспертиза, включающая анализ интересов человека и социума, не должна претендовать на статус истинности, не может носить характер однозначной оценки» (Туманов 2017: 109)?

Вариативность социальных и культурных позиций различных агентов, вариативность аксиологических систем и культурных канонов, вариативность концептуальных оснований самой экспертизы в полной мере охватывает методологическую специфику гуманитарного познания, одновременно понимающего и оценивающего отношения к действительности. Гуманитарная экспертиза оперирует определенными культурными смыслами и идеями и направлена на смысловой уровень социокультурной действительности в качестве своего основного предмета. Гуманитарная экспертиза - это попытка пролить свет на извечную проблему исследователей социальной реальности: что происходит и что за этим кроется. Ее задача - предложить авторскую, подкрепленную теми или иными авторитетами интерпретацию фактов, эксплицировать смысл и значение происходящего применительно к антропологическому, психологическому, социальному бытию человека.

Говоря о современном статусе и перспективах гуманитарной экспертизы, нельзя не отметить увеличение дистанции между гуманностью и гуманитарностью в первую очередь благодаря обозначившейся тенденции системного воспроизводства социогуманитарных технологий. На сегодняшний день специфику социальной реальности определяют не только информационно-коммуникационные технологии, но и технологии, использующие информационно-коммуникативные, когнитивные, психологические и прочие гуманитарные разработки для воздействия на индивида и социальные общности.

Информационно-технологическая революция через соответствующую инфраструктуру послужила катализатором экспоненциального расширения масштабов проектирования и распространения социально-гуманитарных технологий, направленных на изменение сознания и поведения людей посредством специальным образом организованного информационного воздействия. Через регламентацию, алгоритмизацию и рефлексивный контроль механизмов влияния обеспечивается их адресность и контролируется эффективность. Обилие информационных средств и сред, глубина их интеграции в жизнь современного человека многократно усиливает возможности социально-инженерного воздействия. Объектом воздействия социальных технологий становятся не только деятельность и поведение, но и мышление, эмоции, чувства, симпатии и антипатии как индивидов, так и социальных общностей в целом. Конвергенция экспоненциально возрастающих информационно-коммуникационных технологий с эффективными средствами когнитивного, психологического, идеологическо- 
го, аффективно-эмоционального воздействия актуализирует задачу междисциплинарного изучения и оценки феномена социогуманитарных технологий во всем многообразии сфер их применения, привлекаемых инструментов и реализуемых целей.

Коммодификация человекомерных технологий служит движущей силой развития экспертной деятельности в данном направлении. Очевидно, что при коммерческом использовании фактор эффективности выходит на первый план, а ценностный и научный выполняют инструментальные функции. Сфокусированная вокруг подобных прагматических целей экспертиза с необходимостью оказывается редуцированной именно рамками «заказа». Назначение ее продуктов - улучшение действующих технологий и конструирование новых. Практичность и эффективность здесь выступают и как критерии истины, и как критерии блага. Это одновременно вызов и источник новых возможностей для гуманитарной экспертизы.

Гуманитарная экспертиза сегодня - это возможность критического осмысления социотехнологической реальности, ориентированной на максимизацию использования человеческого капитала. «Развенчивание ремифологизированного мира современной культуры (...) и есть та предельная функция гуманитарного эксперта» (Соколовский 1992: 163).

Как было показано выше, гуманитарная экспертиза функционирует в двух ипостасях - как критик и как хранитель традиционных принципов гуманизма. Так, Б.Г. Юдин говорит о гуманитарной экспертизе как социальной практике, сутью которой является «защита человека в той мере и в тех ситуациях, когда он подвергается воздействию (...) многочисленных новых технологий, включая технологии социальные» (Юдин 2008: 150). Однако «будущее, которое уже началось», помимо традиционных консервативной и критической позиции, актуализирует социальный запрос на проективное содержание гуманитарной экспертизы - альтернативные аксиологические и коммуникативные стратегии, способствующие гуманизации социальной практики.

\section{Библиография}

Bakštanovskij, V.I., Sogomonov, A.Û. (1992). «Demokratičeskaâ èkspertiza»: vybor po Buridanu. V: Gumanitarnaâ èkspertiza: vozmožnosti i perspektivy: sbornik naučnyh. trudov. Rossijskâa akademiâ nauk, Sibirskoe otdelenie, Institut problem osvoeniâ Severa, Centr prikladnoj ètiki. Novosibirsk: Nauka. Sibirskoe otdelenie: 191-210 [Бакштановский, В.И., Согомонов, А.Ю. (1992). «Демократическая экспертиза»: выбор по Буридану. В: Гуманитарная экспертиза: возможности и перспективы: сборник научных трудов. Российская академия наук, Сибирское отделение, Институт проблем освоения Севера, Центр прикладной этики. Новосибирск: Наука. Сибирское отделение: 191-210].

Bogomâkov, V.G. (1992). Smysl gumanitarnoj èkspertizy. V: Gumanitarnâ̂ èkspertiza: vozmožnosti i perspektivy: sbornik naučnyh. trudov. Rossijskaâ akademiâ nauk, Sibirskoe otdelenie, Institut problem osvoeniâ Severa, Centr prikladnoj ètiki. Novosibirsk: Nauka. Sibirskoe otdelenie: 109128 [Богомяков, В.Г. (1992). Смысл гуманитарной экспертизы. В: Гуманитарная экспертиза: возможности и перспективы: сборник научных трудов. Российская академия наук, 
Сибирское отделение, Институт проблем освоения Севера, Центр прикладной этики. Новосибирск: Наука. Сибирское отделение: 109-128].

Franc, A.B. (1992). Kto zakažet èkspertizu? V: Gumanitarnaâ èkspertiza: vozmožnosti i perspektivy: sbornik naučnyh. trudov. Rossijskaâ akademiâ nauk, Sibirskoe otdelenie, Institut problem osvoeniâ Severa, Centr prikladnoj ètiki. Novosibirsk: Nauka. Sibirskoe otdelenie: 210-215 [Франц, А.Б. (1992). Кто закажет экспертизу? В: Гуманитарная экспертиза: возможности и перспективы: сборник научных трудов. Российская академия наук, Сибирское отделение, Институт проблем освоения Севера, Центр прикладной этики. Новосибирск: Наука. Сибирское отделение: 210-215].

Ivančenko, G.V., Leont'ev, D.A. (2008). Kompleksnaâ gumanitarnaâ èkspertiza: metodologiâ i smysl. Moskva: Smysl [Иванченко, Г.В., Леонтьев, Д.А. (2008). Комплексная гуманитарная экспертиза: методология и смысл. Москва: Смысл].

Leont’ev, D.A., Tul'činskij, G.L. (2018). Èkspertiza kak gumanitarnaâ metodologiâ i praktika: kruglyj stol «Ot psiholingvističeskoj k kompleksnoj gumanitarnoj èkspertize». Filosofskie nauki, 2: 120140 [Леонтьев, Д.А., Тульчинский, Г.Л. (2018). Экспертиза как гуманитарная методология и практика: круглый стол «От психолингвистической к комплексной гуманитарной экспертизе». Философские науки, 2: 120-140]. DOI: 10.30727/0235-1188-2018-2-120-140.

Moiseev, V.I. (2009). Global'no-strategičeskij kontekst problemy gumanitarnoj èkspertizy innovacionnyh proektov. V: Bioètika i gumanitarnầ èkspertiza: kompleksnoe izučenie čeloveka i virtualistika. T. 3. Moskva: Institut filosofii Rossijskoj akademii nauk, 139-155 [Моисеев, В.И. (2009). Глобальностратегический контекст проблемы гуманитарной экспертизы инновационных проектов. В: Биоэтика и гуманитарная экспертиза: комплексное изучение человека и виртуалистика. Вып. 3. Москва: Институт философии Российской академии наук: 139-155].

Sokolovskij, S.V. (1992). Figura gumanitarnogo èksperta v sovremennoj kul'ture. V: Gumanitarnaâ èkspertiza: vozmožnosti i perspektivy: sbornik naučnyh. trudov. Rossijskaâ akademiâ nauk, Sibirskoe otdelenie, Institut problem osvoeniâ Severa, Centr prikladnoj ètiki. Novosibirsk: Nauka. Sibirskoe otdelenie: 156-167 [Соколовский, С.В. (1992). Фигура гуманитарного эксперта в современной культуре. В: Гуманитарная экспертиза: возможности и перспективы: сборник научных трудов. Российская академия наук, Сибирское отделение, Институт проблем освоения Севера, Центр прикладной этики. Новосибирск: Наука. Сибирское отделение: 156-167].

Tiŝenko, G.È. (2008). Ugroza množestvennosti i ideâ gumanitarnoj èkspertizy. Bioètika igumanitarnaâ èkspertiza, 2: 102-128 [Тищенко, Г.Э. (2008). Угроза множественности и идея гуманитарной экспертизы. Биоэтика и гуманитарная экспертиза, 2: 102-128].

Tul'činskij, G.L. (2008) Gumanitarnaâ èkspertiza kak social’naâ tehnologiâ. Vestnik Čelâbinskoj gosudarstvennoj akademii kul'tury i iskusstv, 2: 38-52 [Тульчинский, Г.Л. (2008). Гуманитарная экспертиза как социальная технология. Вестник Челябинской государственной академии культуры и искусств, 2: 38-52].

Tumanov, S.V., Onosova, A.A, Savina, N.E. (2017). Gumanitarnaâ èkspertiza: teoretičeskie podhody i praktiki ih realizacii. Vestnik Moskovskogo universiteta, Seria 7: Filosofiâ, 5: 107-108 [Туманов, С.В., Оносов, А.А., Савина, Н.Е. (2017). Гуманитарная экспертиза: теоретические подходы и практики их реализации. Вестник Московского университета, Серия 7: Философия, 5: 107-108].

Ûdin, B.G. (2008). Tehnonauka, čelovek, obŝestvo: aktual'nost' gumanitarnoj èkspertizy. Vek globalizacii, 2: 146-154 [Юдин, Б.Г. (2008). Технонаука, человек, общество: актуальность гуманитарной экспертизы. Век глобализации, 2: 146-154]. 